Article

\title{
Synthesis, Crystal Structure, and Kinetics of the Thermal Decomposition of the Nickel(II) Complex of the Schiff Base 2-[(4-Methylphenylimino)methyl]-6-methoxyphenol
}

\author{
Yan-Fang Wang ${ }^{1,2}$, Jian-Feng Liu ${ }^{1}$, Hui-Duo Xian ${ }^{1}$ and Guo-Liang Zhao ${ }^{1, *}$ \\ 1 Zhejiang Key Laboratory for Reactive Chemistry on Solid Surfaces, Institute of Physical \\ Chemistry, College of Chemistry and Life Science, Zhejiang Normal University, Jinhua, 321004, \\ China \\ 2 Ningbo Tian Yi College of Occupation and Technology, Ningbo, Zhejiang 315100, China; \\ E-mails: yfw901@163.com (Y-F.W.); liujianfeng23@163.com (J-F.L.); \\ hdxian@163.com (H-D.X.) \\ * Author to whom correspondence should be addressed; E-mail: sky53@zjnu.cn; \\ Tel.: +86-579-82283925, Fax: +86-579-82282595
}

Received: 25 May 2009; in revised form: 29 June 2009 / Accepted: 13 July 2009 / Published: 15 July 2009

\begin{abstract}
A new dinuclear complex, $\left[\mathrm{Ni}_{2}\left(\mathrm{H}_{2} \mathrm{O}\right) \mathrm{L}_{4}\right] \cdot 5 \mathrm{H}_{2} \mathrm{O}$, consisting of chelating bidentate and bridging tridentate coordinated 2-[(4-methylphenylimino)methyl]-6-methoxyphenol (HL) Schiff base ligands and water molecules has been synthesized using a traditional method. The structure of this complex was characterized by FTIR and UV/Vis spectroscopy and thermogravimetric analyses (TG-DTG) and further confirmed by singlecrystal X-ray diffraction. Its crystal structure is of monoclinic system, space group P21/c with $\mathrm{a}=13.2837(5) \AA, \mathrm{b}=27.3886(10) \AA, \mathrm{c}=17.5415(6) \AA, \alpha=90^{\circ}, \beta=108.429(2)^{\circ}, \gamma$ $=90^{\circ}, \mathrm{V}=6054.7(4) \AA^{3}, \mathrm{Z}=4$. The crystal structure reveals that there is a $\mathrm{Ni} \cdot \mathrm{Ni}$ core, with a separation of $3.183 \AA$. Its thermal decomposition kinetics were also studied.
\end{abstract}

Keywords: dinickel complex; crystal structure; Schiff base 


\section{Introduction}

Polynuclear transition metal complexes have been receiving considerable attention for many years, due to their interesting characteristics in the fields of material science and biological systems [1,2]. oVanillin is considered a safe food flavoring and can be used as a pharmaceutical intermediate $[3,4]$, and because of the wide applications o-vanillin derivatives and their complexes have drawn much attention [5-8]. Schiff base ligands which usually contain $\mathrm{O}, \mathrm{N}$ donor atoms have played an important role in coordination chemistry since the late 19th century. Metal complexes with these ligands are becoming increasingly important as biochemical, analytical and antimicrobial reagents, in the design of molecular magnets, materials chemistry and so on [9 14]. The versatile properties of the ligand 2[(4-methyl-phenylimino)methyl]-6-methoxyphenol (HL) in the formation of diverse transition metal complexes are well known. We have synthesized some complexes from HL, with discrete, dinuclear and polynuclear structures [15 17]. In continuation of the research in our group, we now describe a detailed investigation on the synthesis, single X-ray crystallographic and kinetics of the thermal decomposition of $\left[\mathrm{Ni}_{2}\left(\mathrm{H}_{2} \mathrm{O}\right) \mathrm{L}_{4}\right] \cdot 5 \mathrm{H}_{2} \mathrm{O}(\mathbf{1})$.

\section{Results and Discussion}

\subsection{IR spectra}

Important information obtained from the IR spectra of HL and complex $\mathbf{1}$ is summarized in Table 1. The broad absorption bands at about $3,444 \mathrm{~cm}^{-1}$, attributed to the $v(\mathrm{O}-\mathrm{H})$, indicate the presence of water in this compound. In addition, the band appearing at $615 \mathrm{~cm}^{-1}$ and resulting from $\delta(\mathrm{O}-\mathrm{H})$ bends also supports this conclusion. Some sharp bands appearing at about $2,962 \mathrm{~cm}^{-1}$ and $1,380 \mathrm{~cm}^{-1}$ belong to the $v(\mathrm{C}-\mathrm{H})$ and $\delta(\mathrm{C}-\mathrm{H})$ of methyl group and methoxyl groups. The characteristic absorption bands resulting from the skeletal vibrations of the aromatic rings from the Schiff base ligands are in the $1,400-1,600 \mathrm{~cm}^{-1}$ region $\left(1,597 \mathrm{~cm}^{-1}, 1,508 \mathrm{~cm}^{-1}\right.$ and $\left.1,470 \mathrm{~cm}^{-1}\right)$. The typical $v(\mathrm{C}=\mathrm{N})$ band at $1,641 \mathrm{~cm}^{-1}$ in the spectrum of HL changes to $1,619 \mathrm{~cm}^{-1}$ after the imine $\mathrm{N}$ bonds to the metal ion. The shift of the $\mathrm{C}-\mathrm{O}$ stretching vibration of the phenolic part of $o$-vanillin from $1,257 \mathrm{~cm}^{-1}$ to $1,238 \mathrm{~cm}^{-1}$ also supports the coordination of phenolic oxygen atoms. At last, the new band appearing at $509 \mathrm{~cm}^{-1}$ is attributed to $\mathrm{M}-\mathrm{O}$ stretching vibration, which is absent in ligand spectra [18].

Table 1. Values of IR spectra for complex 1 and $\mathrm{HL}\left(\mathrm{cm}^{-1}\right)$.

\begin{tabular}{ccccc}
\hline Compound & v OH & v C=N & v C-O & v M-O \\
\hline $\mathrm{HL}$ & $3468(\mathrm{w})$ & $1614(\mathrm{~s})$ & $1257(\mathrm{~s})$ & - \\
{$\left[\mathrm{Ni} 2\left(\mathrm{H}_{2} \mathrm{O}\right) \mathrm{L} 4\right] \cdot 5 \mathrm{H}_{2} \mathrm{O}$} & $3444(\mathrm{~m})$ & $1619(\mathrm{~s})$ & $1238(\mathrm{~s})$ & $509(\mathrm{w})$ \\
\hline
\end{tabular}

* Note: s: strong, m: middle, w: weak.

\subsection{UV/Vis spectra}

The absorptions in the UV/Vis spectra of HL and complex 1 are similar (Figure 1). There are three absorption peaks in the range of 200 500 nm at 317.8, 276.0 and $228.0 \mathrm{~nm}$ in the spectra of HL. The counterparts of the complex appear at $301.4,292.0$ and $229.8 \mathrm{~nm}$. The first peak is assigned to $\mathrm{n}-\pi^{*}$ 
transition of conjugation between lone-pair electron $\mathrm{N}$ atom in the $\mathrm{C}=\mathrm{N}$ group and big $\pi$ bond of benzene ring. The hypsochromic shift of about $16 \mathrm{~nm}$ is caused by the coordination of $\mathrm{N}$ atom to $\mathrm{Ni}$ ion, which can also provide the conclusion evidence for the coordination. The other two peaks are attributed to $\pi-\pi^{*}$ transition of the conjugation system of Schiff base and they are similar in HL and in the complex.

Figure 1. The UV/vis spectra of the complex 1 and the ligand HL.

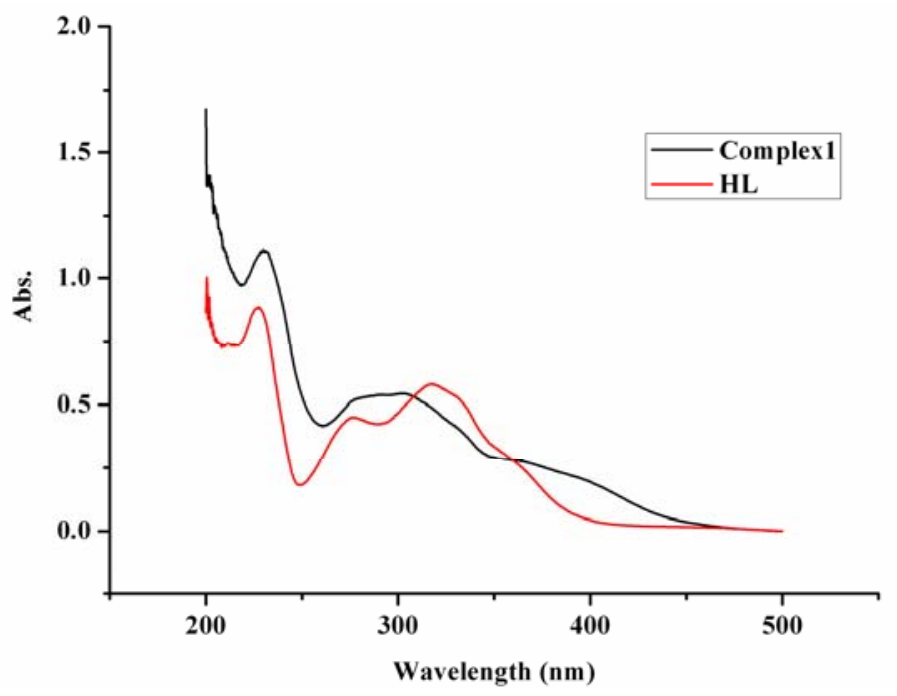

\subsection{Crystal structure}

The complex is an asymmetric dinuclear nickel complex and there is no significant metal-metal interaction between the two nickel centers considering of the separation of $\mathrm{Ni}(1) \cdots \mathrm{Ni}(2)$ is 3.1831(3) $\AA$, which is longer than that of previously reported dinickel complexes [19]. The environments of the two nickel atoms are very similar to each other; both are six-coordinate, coordinated to four oxygen and two nitrogen atoms in a slightly distorted octahedron, although there are still some differences such as $\mathrm{Ni}(1)$ is bound by four $\mathrm{O}$ atoms $(\mathrm{O} 4, \mathrm{O} 7, \mathrm{O} 10, \mathrm{O} 1 \mathrm{w})$ coming from three different phenolic groups of Schiff base (L1, L2, L3) ligands and a coordinated water molecule, where the Ni-O bond distances range from $1.9410(10)$ to $2.3389(10) \AA$, whereas the four $\mathrm{O}$ atoms that surround $\mathrm{Ni}(2)$ come from three Schiff base molecules (L1, L3, L4), and the bond distances are from 2.0048(10) to 2.2876(9) A. To the best of our knowledge, this is the first example of a crystallographically characterized complex with four 2-[(4-methylphenylimino)methyl]-6-methoxyphenol Schiff base ligands with three types of coordination modes in one complex: (i) simple N,O-chelating bidentate [Figure 3 (a)] L2 and L4 belong to this mode, and they chelate to $\mathrm{Ni}(1)$ and $\mathrm{Ni}(2)$ respectively, the coordinated atoms are both phenolic $\mathrm{O}$ and imino $\mathrm{N}$; (ii) bidentate [Figure 3 (b)] L3 chelates to $\mathrm{Ni}(2)$ with phenolic $\mathrm{O}$ and imino $\mathrm{N}$, and the phenolic $\mathrm{O}$ also bridges to $\mathrm{Ni}(1)$; (iii) bridging quadridentate [Figure 3 (c)], this mode is adopted by $\mathrm{L}$. In addition to the phenolic $\mathrm{O}$ and imino $\mathrm{N}$, the methoxyl $\mathrm{O}$ is also involved in the coordination to $\mathrm{Ni}$. These are apparently important for rational design and constitution of new framework structures. The main bond lengths and bond angles are listed in Table. 7. Two methoxyphenol rings of the L2 and L3 ligand are almost parallel to each other with a dihedral angels $13.91^{\circ}$, and the center distance of which is $3.85 \AA$ indicated a weak $\pi \cdots \pi$ stacking interaction[20]. There are 
several water molecules involved in $\mathrm{O}-\mathrm{H} \cdots \mathrm{O}$ intramolecular hydrogen-bonding interactions, which help to stabilize this structure.

Figure 2. Molecular structure of the complex 1 (probability of ellipsoid is $30 \%$ ). All the non-coordinated water molecules are omitted for clarity.

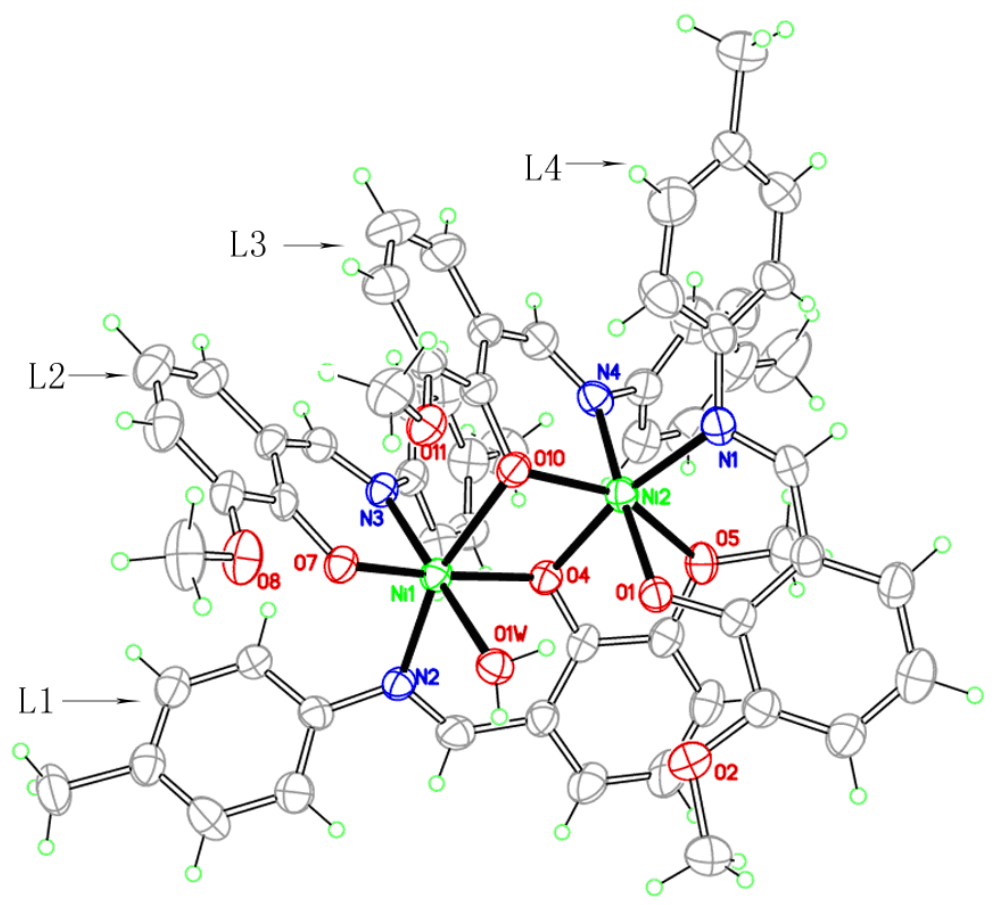

Figure 3. The three coordinate modes of $\mathrm{L}$ in complex 1.<smiles>COc1cccc2c[Y13](-c3ccc(C)cc3)oc12</smiles>

(a)<smiles>[M]OCc1c(/C=N\N(C)c2ccc(C)cc2)cccc1OC</smiles>

(b)<smiles>COCCN/N=C\c1cccc(OC)c1OC</smiles>

(c)

\subsection{Thermal analysis}

The TG-DTG curve of complex 1 is shown in Figure 4. There are three main weight loss stages for the decomposition process. In the first stage, from $76{ }^{\circ} \mathrm{C} \sim 152{ }^{\circ} \mathrm{C}, 9.14 \%$ of the weight is lost, which corresponds to the loss of six water molecules, which coincides with the calculated value $9.10 \%$. The 
temperature range of $226{ }^{\circ} \mathrm{C} \sim 413{ }^{\circ} \mathrm{C}$ is the second stage, with a weight loss of about $59.46 \%$ and it seems that three Schiff ligand molecules has burned off (calcd. 61.00\%). The remaining one cannot remain too long, and its loss accounts for the third stage with a loss of $15.60 \%$ in the temperature range of $431{ }^{\circ} \mathrm{C} \sim 460{ }^{\circ} \mathrm{C}$ (the calculated value is $13.95 \%$ ). The remaining mass of $15.50 \%$ seems likely to correspond to $\mathrm{NiO}$ (calcd. 12.56\%).

Figure 4. The TG-DTG curves of complex 1.

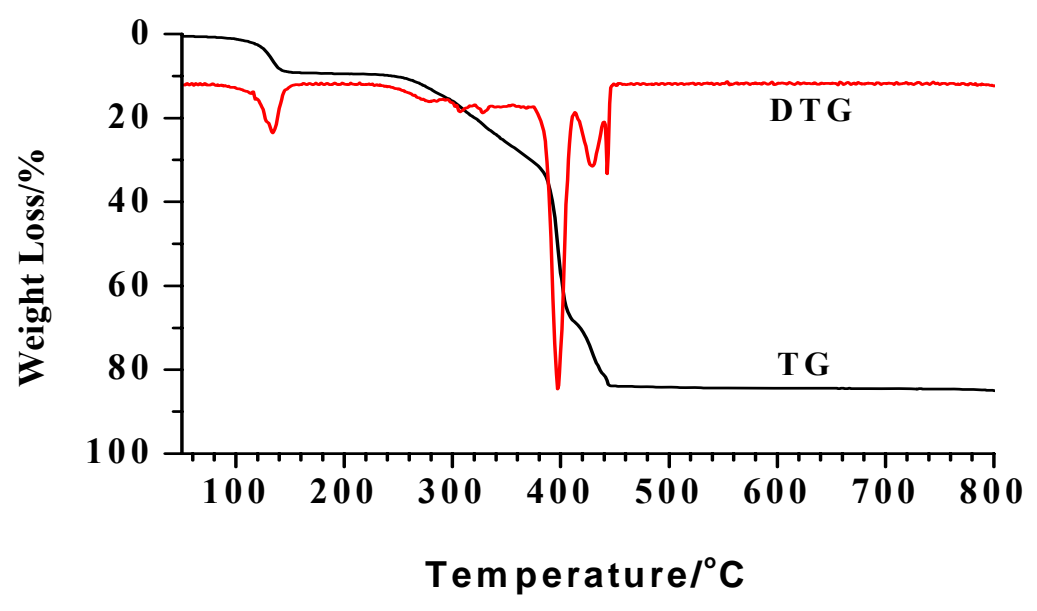

\subsection{Non-isothermal kinetics for Steps 1 and 2}

For the TG and DTG curves, the non-isothermal kinetic data in the steps 1 and 3 of the thermal decomposition were analyzed by means of differential and integral methods. The differential equation used was proposed by Achar et al [21,22]. The integral equation was Coats-Redfern equation [23]. The used forms $\mathrm{f}(\alpha)$ and $\mathrm{g}(\alpha)$ are listed in Table 2. The original data for Steps 1 and 3 determined from the TG-DTG curves are listed in Table 3.

Archar equation:

$$
\ln [(\mathrm{d} \alpha / \mathrm{dt}) / \mathrm{f}(\alpha)]=\ln \mathrm{A}-\mathrm{E} /(\mathrm{RT})
$$

Coats-Redfern equation:

$$
\ln \left[\mathrm{g}(\alpha) / \mathrm{T}^{2}\right]=\ln (\mathrm{AR}) /(\beta \mathrm{E})-\mathrm{E} /(\mathrm{RT})
$$

In the above equations, $\alpha$ is the fraction of the reacted material, $\mathrm{T}$ is the absolute temperature and $\mathrm{f}(\alpha)$ and $\mathrm{g}(\alpha)$ are differential and integral mechanism functions, respectively. E and $\mathrm{A}$ are the derived apparent activation energy and pre-exponential factor, respectively, $\mathrm{R}$ is the gas constant and $\beta$ is the heating rate.

The kinetic analysis was performed by the linear least square method. The results of the kinetic parameters E, A and correlation coefficients $r$ for step 1 and 2 are shown in Table 3.

We fitted the kinetic parameters obtained (E and $\mathrm{A}$ ) using the equations of Achar et al. and CoatsRedfern (see Table 4). Comparing the results from the differential and integral methods, we found that the values of $\mathrm{E}$ and $\mathrm{A}$ were acceptable and the linear correlation coefficients were also better when the possible mechanism functions were rational selected. 
Table 2. Some integral and differential coefficient kinetic functions.

\begin{tabular}{|c|c|c|c|}
\hline $\begin{array}{c}\text { Symbo } \\
1\end{array}$ & $\begin{array}{c}\text { Integral kinetic } \\
\text { function }\end{array}$ & $\begin{array}{c}\text { Differential coefficient } \\
\text { kinetic function }\end{array}$ & Mechanism \\
\hline D1 & $\alpha^{2}$ & $1 /(2 \alpha)$ & One-dimensional diffusion \\
\hline D2 & $\alpha+(1-\alpha) \ln (1-\alpha)$ & {$[-\ln (1-\alpha)]^{-1}$} & Two-dimensional diffusion \\
\hline 1D3 & $1-(2 / 3) \alpha-(1-\alpha)^{2 / 3}$ & $3 / 2\left[(1-\alpha)^{-1 / 3}-1\right]^{-1}$ & $\begin{array}{l}\text { Three-dimensional diffusion } \\
\text { (cylindrical symmetry) }\end{array}$ \\
\hline 2D3 & {$\left[1-(1-\alpha)^{1 / 3}\right]^{2}$} & $3 / 2(1-\alpha)^{2 / 3}\left[1-(1-\alpha)^{1 / 3}\right]^{-1}$ & $\begin{array}{l}\text { Three-dimensional diffusion } \\
\text { (spherical symmetry) }\end{array}$ \\
\hline 3D3 & {$\left[(1+\alpha)^{1 / 3}-1\right]^{2}$} & $3 / 2(1+\alpha)^{2 / 3}\left[(1+\alpha)^{1 / 3}-1\right]^{-1}$ & Three-dimensional diffusion \\
\hline 4D3 & {$\left[1 /(1-\alpha)^{1 / 3}-1\right]^{1 / 2}$} & $3 / 2(1-\alpha)^{4 / 3}\left[1 /(1-\alpha)^{1 / 3}-1\right]^{-1}$ & Three-dimensional diffusion \\
\hline A1 & $-\ln (1-\alpha)$ & $(1-\alpha)$ & $\begin{array}{l}\text { Random nucleation and nuclei } \\
\text { growth }(\mathrm{n}=1)\end{array}$ \\
\hline A 1.5 & {$[-\ln (1-\alpha)]^{2 / 3}$} & $3 / 2(1-\alpha)[-\ln (1-\alpha)]^{1 / 3}$ & $\begin{array}{l}\text { Random nucleation and nuclei } \\
\text { growth }(\mathrm{n}=1.5)\end{array}$ \\
\hline $\mathrm{A} 2$ & {$[-\ln (1-\alpha)]^{1 / 2}$} & $2(1-\alpha)[-\ln (1-\alpha)]^{1 / 2}$ & $\begin{array}{l}\text { Random nucleation and nuclei } \\
\text { growth }(\mathrm{n}=2)\end{array}$ \\
\hline A3 & {$[-\ln (1-\alpha)]^{1 / 3}$} & $3(1-\alpha)[-\ln (1-\alpha)]^{2 / 3}$ & $\begin{array}{l}\text { Random nucleation and nuclei } \\
\text { growth }(\mathrm{n}=3)\end{array}$ \\
\hline A4 & {$[-\ln (1-\alpha)]^{1 / 4}$} & $4(1-\alpha)[-\ln (1-\alpha)]^{3 / 4}$ & $\begin{array}{l}\text { Random nucleation and nuclei } \\
\text { growth }(\mathrm{n}=4)\end{array}$ \\
\hline $\mathrm{R} 2$ & $1-(1-\alpha)^{1 / 2}$ & $2(1-\alpha)^{1 / 2}$ & $\begin{array}{l}\text { Contracting sphere (cylindrical } \\
\text { symmetry) }\end{array}$ \\
\hline R3 & $1-(1-\alpha)^{1 / 3}$ & $3(1-\alpha)^{2 / 3}$ & $\begin{array}{l}\text { Contractingsphere } \\
\text { (spherical symmetry) }\end{array}$ \\
\hline $\mathrm{P} 1$ & $\alpha$ & 1 & Exponential nucleation \\
\hline $\mathrm{P} 2$ & $\alpha^{1 / 2}$ & $2 \alpha^{1 / 2}$ & Exponential nucleation \\
\hline P3 & $\alpha^{1 / 3}$ & $3 \alpha^{2 / 3}$ & Exponential nucleation \\
\hline P4 & $\alpha^{1 / 4}$ & $4 \alpha^{3 / 4}$ & Exponential nucleation \\
\hline $\mathrm{C} 2$ & $(1-\alpha)^{-1}-1$ & $(1-\alpha)^{2}$ & Chemical reaction \\
\hline $\mathrm{C} 1.5$ & $(1-\alpha)^{-1 / 2}$ & $2(1-\alpha)^{3 / 2}$ & Chemical reaction \\
\hline
\end{tabular}

Table 3. Kinetic compensation parameters for Step 1 and Step 2.

\begin{tabular}{lll||lll}
\hline \multicolumn{3}{c||}{ Step 1 } & \multicolumn{3}{c}{ Step 2 } \\
\hline $\mathbf{T} / \mathbf{K}$ & $\boldsymbol{\alpha}$ & $\mathbf{d} \boldsymbol{\alpha} / \mathbf{d t}$ & $\mathbf{T} / \mathbf{K}$ & $\boldsymbol{\alpha}$ & $\mathbf{d \alpha} / \mathbf{d t}$ \\
\hline 363.15 & 0.0204 & 2.1941 & 493.15 & 0.0158 & 2.5213 \\
373.15 & 0.0548 & 1.8824 & 503.15 & 0.0416 & 1.3356 \\
383.15 & 0.1163 & 1.5496 & 513.15 & 0.0930 & 1.8930 \\
393.15 & 0.2237 & 1.6131 & 523.15 & 0.1888 & 1.6043 \\
403.15 & 0.4937 & 1.8258 & 533.15 & 0.3547 & 1.3785 \\
413.15 & 0.9043 & 0.6285 & 543.15 & 0.6250 & 1.2225 \\
\hline
\end{tabular}


Table 4. The kinetic data of thermal decomposition of Step 1.

\begin{tabular}{ccccccc}
\hline & \multicolumn{3}{c}{ Achar method } & \multicolumn{3}{c}{ Coats-Redfern method } \\
\hline No. & $E / \mathrm{kJ} \mathrm{mol}^{-1}$ & $\mathrm{~A} / \mathrm{s}^{-1}$ & $r$ & $E / \mathrm{kJ} \mathrm{mol}^{-1}$ & $A / \mathrm{s}^{-1}$ & $r$ \\
1 & 207.59 & $2.18 \mathrm{E}+06$ & 0.9548 & 171.38 & $3.37 \mathrm{E}+20$ & 0.9989 \\
2 & 265.51 & $4.98 \mathrm{E}-03$ & 0.9914 & 181.63 & $5.40 \mathrm{E}+21$ & 0.9990 \\
3 & 290.10 & $8.78 \mathrm{E}+02$ & 0.9947 & 185.89 & $5.06 \mathrm{E}+21$ & 0.9986 \\
4 & 336.58 & $8.53 \mathrm{E}-12$ & 0.9905 & 194.64 & $9.66 \mathrm{E}+22$ & 0.9970 \\
5 & 162.82 & $4.90 \mathrm{E}-14$ & 0.9032 & 161.29 & $1.20 \mathrm{E}+18$ & 0.9980 \\
6 & 475.99 & $2.52 \mathrm{E}+00$ & 0.9573 & 224.61 & $2.31 \mathrm{E}+27$ & 0.9867 \\
7 & 74.73 & $1.27 \mathrm{E}+02$ & 0.7679 & 101.24 & $3.26 \mathrm{E}+11$ & 0.9926 \\
8 & -35.34 & $1.16 \mathrm{E}-05$ & 0.5499 & 65.41 & $3.97 \mathrm{E}+06$ & 0.9922 \\
9 & 36.58 & $2.58 \mathrm{E}-16$ & 0.6520 & 47.49 & $1.25 \mathrm{E}+04$ & 0.9918 \\
10 & -145.40 & $6.08 \mathrm{E}-20$ & 0.9530 & 29.57 & $3.38 \mathrm{E}+01$ & 0.9907 \\
11 & -172.92 & $8.57 \mathrm{E}-22$ & 0.9683 & 20.61 & $1.55 \mathrm{E}+00$ & 0.9894 \\
12 & 5.02 & $4.07 \mathrm{E}+17$ & 0.1679 & 90.98 & $4.87 \mathrm{E}+09$ & 0.9981 \\
13 & 28.25 & $4.70 \mathrm{E}+11$ & 0.6219 & 94.19 & $9.74 \mathrm{E}+09$ & 0.9969 \\
14 & -64.69 & $1.16 \mathrm{E}-05$ & 0.7463 & 82.55 & $5.37 \mathrm{E}+08$ & 0.9988 \\
15 & -200.83 & $2.58 \mathrm{E}-16$ & 0.9640 & 38.14 & $4.51 \mathrm{E}+02$ & 0.9986 \\
16 & -246.21 & $6.08 \mathrm{E}-20$ & 0.9761 & 23.34 & $3.37 \mathrm{E}+00$ & 0.9983 \\
17 & -268.90 & $8.57 \mathrm{E}-22$ & 0.9799 & 15.94 & $2.54 \mathrm{E}-01$ & 0.9979 \\
18 & 214.14 & $4.07 \mathrm{E}+17$ & 0.7969 & 127.51 & $2.47 \mathrm{E}+15$ & 0.9673 \\
19 & 144.43 & $4.70 \mathrm{E}+11$ & 0.7922 & 16.21 & $6.03 \mathrm{E}-01$ & 0.6840 \\
\hline
\end{tabular}

Thus we deduced that the possible mechanism for the step 1 of thermal decomposition of the complex was a 1D3 chemical reaction. The corresponding non-isothermal kinetic equation was:

$$
f(\alpha)=2 / 3\left[(1-\alpha)^{-1 / 3}-1\right]^{-1}, g(\alpha)=1-(2 / 3) \alpha-(1-\alpha)^{2 / 3}
$$

The average values of the apparent activation energy $\mathrm{E}$ and pre-exponential factor A were 239.00 $\mathrm{kJ} \cdot \mathrm{mol}^{-1}$ and 0.9967 , respectively.

The possible mechanism for step 2 was 2D3 chemical reaction. The corresponding non-isothermal kinetic equation was

$$
f(\alpha)=3 / 2(1-\alpha)^{2 / 3}\left[1-(1-\alpha)^{1 / 3}\right]^{-1}, g(\alpha)=\left[1-(1-\alpha)^{1 / 3}\right]^{2}
$$

The average values of the apparent activation energy E and pre-exponential factor A were 376.34 $\mathrm{kJ} \cdot \mathrm{mol}^{-1}$ and 0.9962 , respectively.

From the thermal analysis, we can see the decomposition procession of the complex is complicated. For infer the mechanism of the thermal decomposition, we analyzed the non-isothermal kinetic in two decomposition steps by means of differential and integral methods. We have found the proper mechanism functions of the two steps and their decomposition activation energy. 
Table 5. The kinetic data of thermal decomposition of Step 2.

\begin{tabular}{ccccccc}
\hline & \multicolumn{3}{c}{ Achar method } & \multicolumn{3}{c}{ Coats-Redfern method } \\
\hline No. & $\mathrm{E} / \mathrm{kJ} \mathrm{mol}^{-1}$ & $\mathrm{~A} / \mathrm{s}^{-1}$ & $\mathrm{r}$ & $\mathrm{E} / \mathrm{kJ} \mathrm{mol}^{-1}$ & $\mathrm{~A} / \mathrm{s}^{-1}$ & $\mathrm{r}$ \\
1 & 325.14 & $1.12 \mathrm{E}+21$ & 0.9875 & 317.17 & $3.75 \mathrm{E}+28$ & 0.9974 \\
2 & 366.94 & $3.70 \mathrm{E}+23$ & 0.9927 & 328.16 & $2.72 \mathrm{E}+29$ & 0.9985 \\
3 & 382.33 & $2.02 \mathrm{E}+24$ & 0.9933 & 332.19 & $1.61 \mathrm{E}+29$ & 0.9988 \\
4 & 412.37 & $9.59 \mathrm{E}+25$ & 0.9932 & 340.31 & $1.16 \mathrm{E}+30$ & 0.9992 \\
5 & 276.76 & $6.57 \mathrm{E}+16$ & 0.9760 & 302.95 & $1.28 \mathrm{E}+26$ & 0.9958 \\
6 & 502.52 & $1.16 \mathrm{E}+32$ & 0.9872 & 365.92 & $5.83 \mathrm{E}+32$ & 0.9994 \\
7 & 35.18 & $4.55 \mathrm{E}+02$ & 0.4475 & 172.10 & $4.57 \mathrm{E}+14$ & 0.9995 \\
8 & -105.45 & $3.05 \mathrm{E}-07$ & 0.8205 & 111.86 & $4.83 \mathrm{E}+08$ & 0.9995 \\
9 & 2.73 & $1.46 \mathrm{E}+00$ & 0.0447 & 81.75 & $4.50 \mathrm{E}+05$ & 0.9994 \\
10 & -246.09 & $1.53 \mathrm{E}-16$ & 0.9545 & 51.63 & $3.63 \mathrm{E}+02$ & 0.9994 \\
11 & -281.25 & $6.48 \mathrm{E}-19$ & 0.9638 & 36.57 & $9.18 \mathrm{E}+00$ & 0.9993 \\
12 & -9.90 & $2.07 \mathrm{E}-01$ & 0.1732 & 162.85 & $2.34 \mathrm{E}+13$ & 0.9988 \\
13 & 5.13 & $1.42 \mathrm{E}+00$ & 0.0849 & 165.85 & $3.27 \mathrm{E}+13$ & 0.9992 \\
14 & -54.97 & $3.76 \mathrm{E}-04$ & 0.7347 & 154.28 & $5.67 \mathrm{E}+12$ & 0.9972 \\
15 & -245.03 & $1.54 \mathrm{E}-16$ & 0.9743 & 72.84 & $4.72 \mathrm{E}+04$ & 0.9968 \\
16 & -308.38 & $9.63 \mathrm{E}-21$ & 0.9820 & 45.69 & $7.71 \mathrm{E}+01$ & 0.9963 \\
17 & -340.06 & $6.99 \mathrm{E}-23$ & 0.9844 & 32.12 & $2.77 \mathrm{E}+00$ & 0.9958 \\
18 & 125.33 & $5.51 \mathrm{E}+08$ & 0.7525 & 192.70 & $7.18 \mathrm{E}+16$ & 0.9979 \\
19 & 80.25 & $2.50 \mathrm{E}+05$ & 0.6703 & 10.60 & $1.22 \mathrm{E}-02$ & 0.7115 \\
\hline
\end{tabular}

\section{Experimental}

\subsection{Materials and general methods}

$\mathrm{NiCl}_{2} \cdot 6 \mathrm{H}_{2} \mathrm{O}, o$-vanillin, $p$-toluidine, and other chemical reagents were obtained from commercial sources and used without further purification. The metal contents were determined by EDTA complexometric titration after decomposition a known amount of the complexes with concentrated nitric acid. Elemental analyses for $\mathrm{C}, \mathrm{H}$ and $\mathrm{N}$ were carried out on an Elementar Vario EL III elemental analyzer. IR spectra of $\mathrm{KBr}$ pellets were recorded on a Nicolet NEXUS 670 FTIR spectrophotometer in the range of 4,000-400 $\mathrm{cm}^{-1}$. Thermal analyses were carried out using MettlerToludo TGA/SDTA $851^{\mathrm{e}}$ thermal analyzer with a heating rate of $10{ }^{\circ} \mathrm{C} \cdot \mathrm{min}^{-1}$ from $30{ }^{\circ} \mathrm{C}$ to $800{ }^{\circ} \mathrm{C}$ in an air atmosphere.

\subsection{Syntheses}

$\mathrm{C}_{15} \mathrm{H}_{15} \mathrm{NO}_{2}(\mathrm{HL})$ : Schiff base ligand was prepared by the direct solution reaction of $p$-toluidine (10.0 mmol, $1.07 \mathrm{~g})$ and $o$-vanillin $(0.01 \mathrm{~mol}, 1.52 \mathrm{~g})$ refluxed in ethanol $(\sim 60 \mathrm{~mL})$ on a water bath for $2 \mathrm{~h}$. The solution was cooled to room temperature, and then the red crystals were obtained, washed with absolute ethanol and dried. Yield $1.93 \mathrm{~g}(80 \%)$, m.p. $\sim 100^{\circ} \mathrm{C}$. It was recrystallized from methanol before used. 
Figure 5. Structure of Schiff base ligand.

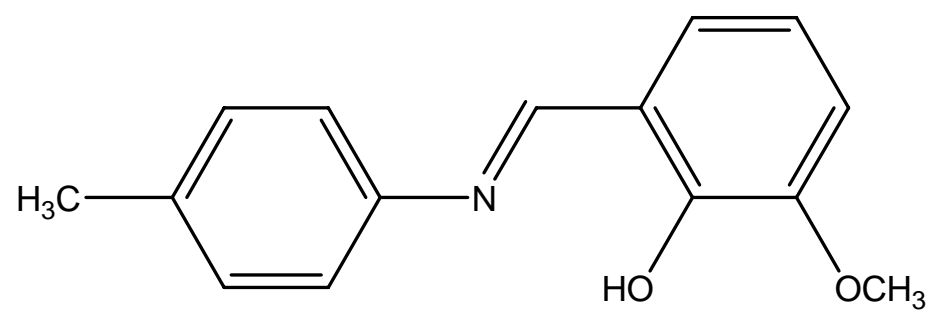

$\left[\mathrm{Ni}_{2}\left(\mathrm{H}_{2} \mathrm{O}\right) \mathrm{L}_{4}\right] \cdot 5 \mathrm{H}_{2} \mathrm{O}(\mathbf{1}): \mathrm{NiCl}_{2} \cdot 6 \mathrm{H}_{2} \mathrm{O}(1 \mathrm{mmol}, 0.237 \mathrm{~g})$ dissolved in anhydrous ethanol $(10 \mathrm{~mL})$ was stirred with HL $(0.57 \mathrm{~g}, 2 \mathrm{mmol})$ in anhydrous ethanol $(20 \mathrm{~mL})$ and refluxed for $2 \mathrm{~h}$ on a water bath, then the solid that deposited after cooling to room temperature was washed with ethanol and dried. Yield $0.80 \mathrm{~g}$ (70\%). Green single crystals of complex 1 were obtained suitable for X-ray diffraction from the mother liquor after five days of slow evaporation at room temperature.

\subsection{Crystal structure determination}

Single crystals of complex 1 was selected and was structurely mesured measured with a Rigaku RAXIS RAPID diffractometer with graphite-monochromated Mo-K $\alpha$ radiation $(\lambda=0.71073 \AA)$ at 296 $\mathrm{K}$. Empirical absorption corrections were applied by use of the ABSCOR program. The structures were solved by direct methods and all calculations were performed with the aid of the SHELXL PC program[24]. The structures were refined by full-matrix, least-squares minimization of $\Sigma\left(\mathrm{F}_{0}-\mathrm{F}_{\mathrm{c}}\right)^{2}$ with anisotropic thermal parameters for all atoms except $\mathrm{H}$ atoms. The crystal data of the complex $\mathbf{1}$ is summarized in Table 6, selected bond lengths and angles are show in Table 7.

Table 6. Crystallographic Data for Complex 1.

\begin{tabular}{ll}
\hline Empirical formula & $\mathbf{C}_{\mathbf{6 0}} \mathbf{H}_{\mathbf{6 8}} \mathbf{N}_{\mathbf{4}} \mathbf{N i}_{\mathbf{2}} \mathbf{O}_{\mathbf{1 4}}$ \\
\hline Formula weight & 1186.60 \\
$\mathrm{~T} / \mathrm{K}$ & $296(2)$ \\
Crystal system & monoclinic \\
Space group & $\mathrm{P} 21 / \mathrm{c}$ \\
$a(\AA)$ & $13.2837(5)$ \\
$b(\AA)$ & $27.3886(10)$ \\
$c(\AA)$ & $17.5415(6)$ \\
$\alpha\left(^{\circ}\right)$ & 90 \\
$\beta\left(^{\circ}\right)$ & $108.429(2)$ \\
$\gamma\left(^{\circ}\right)$ & 90 \\
$V\left(\AA^{3}\right)$ & $6054.7(4)$ \\
$Z$ & 4 \\
Density (g/cm $\left.{ }^{3}\right)$ & 1.302 \\
$M\left(\mathrm{~mm}^{-1}\right)$ & 0.687 \\
$F(000)$ & 2496 \\
Absorption correction & none \\
Data/restrains/parameters & $10668 / 18 / 748$ \\
$\theta$ range ${ }^{\circ}$ & 1.43 to 25.00 \\
\hline
\end{tabular}


Table 6. Cont.

\begin{tabular}{ll}
\hline Limiting indices & $-15<=\mathrm{h}<=15,-32<=\mathrm{k}<=31,-$ \\
& $20<=1<=20$ \\
Reflections collected/ unique & $81485 / 10668$ \\
$\mathrm{R}_{\text {int }}$ & 0.0950 \\
GOOF on $F^{2}$ & 1.032 \\
$R$ and $w R(I>2 \sigma(I))$ & $R=0.0873, w R=0.2594$ \\
$R$ indices $($ all data $)$ & $R=0.1287, w R=0.3012$ \\
$(\Delta \rho)_{\max },(\Delta \rho)_{\min }\left(\mathrm{e} \cdot \AA^{-3}\right)$ & 2.174 and -0.465 \\
\hline
\end{tabular}

Table 7. Selected Bond Lengths $(\AA)$ and Bond Angles $\left(^{\circ}\right)$ for Complex 1.

\begin{tabular}{ll||ll||ll}
\hline Bond & $(\AA)$ & Bond & $(\AA)$ & Bond & $(\AA)$ \\
\hline $\mathrm{Ni}(1)-\mathrm{O}(4)$ & $1.9734(10)$ & $\mathrm{C}(7)-\mathrm{N}(1)$ & $1.2942(19)$ & $\mathrm{C}(18)-\mathrm{O}(5)$ & $1.3658(19)$ \\
$\mathrm{Ni}(1)-\mathrm{O}(7)$ & $1.9410(10)$ & $\mathrm{C}(9)-\mathrm{N}(1)$ & $1.4138(19)$ & $\mathrm{C}(23)-\mathrm{O}(5)$ & $1.450(2)$ \\
$\mathrm{Ni}(1)-\mathrm{O}(10)$ & $2.3389(10)$ & $\mathrm{C}(22)-\mathrm{N}(2)$ & $1.310(2)$ & $\mathrm{C}(32)-\mathrm{O}(7)$ & $1.3041(16)$ \\
$\mathrm{Ni}(1)-\mathrm{O}(1 \mathrm{~W})$ & $2.2364(8)$ & $\mathrm{C}(24)-\mathrm{N}(2)$ & $1.410(2)$ & $\mathrm{C}(33)-\mathrm{O}(8)$ & $1.3614(15)$ \\
$\mathrm{Ni}(1)-\mathrm{N}(2)$ & $2.0680(11)$ & $\mathrm{C}(39)-\mathrm{N}(3)$ & $1.4309(18)$ & $\mathrm{C}(38)-\mathrm{O}(8)$ & $1.436(2)$ \\
$\mathrm{Ni}(1)-\mathrm{N}(3)$ & $2.0898(10)$ & $\mathrm{C}(37)-\mathrm{N}(3)$ & $1.287(2)$ & $\mathrm{C}(47)-\mathrm{O}(10)$ & $1.3431(16)$ \\
$\mathrm{Ni}(2)-\mathrm{O}(1)$ & $2.0253(8)$ & $\mathrm{C}(52)-\mathrm{N}(4)$ & $1.321(2)$ & $\mathrm{C}(48)-\mathrm{O}(11)$ & $1.3759(15)$ \\
$\mathrm{Ni}(2)-\mathrm{O}(4)$ & $2.0602(10)$ & $\mathrm{C}(54)-\mathrm{N}(4)$ & $1.428(2)$ & $\mathrm{C}(53)-\mathrm{O}(11)$ & $1.4333(19)$ \\
$\mathrm{Ni}(2)-\mathrm{O}(5)$ & $2.2876(9)$ & $\mathrm{C}(2)-\mathrm{O}(1)$ & $1.3079(18)$ & & \\
$\mathrm{Ni}(2)-\mathrm{O}(10)$ & $2.0048(10)$ & $\mathrm{C}(3)-\mathrm{O}(2)$ & $1.351(2)$ & & \\
$\mathrm{Ni}(2)-\mathrm{N}(1)$ & $2.0977(13)$ & $\mathrm{C}(8)-\mathrm{O}(2)$ & $1.451(2)$ & & \\
$\mathrm{Ni}(2)-\mathrm{N}(4)$ & $2.0545(10)$ & $\mathrm{C}(17)-\mathrm{O}(4)$ & $1.3049(16)$ & & \\
\hline $\mathrm{Angle}$ & $\left({ }^{\circ}\right)$ & $\mathrm{Angle}$ & $\left({ }^{\circ}\right)$ & & \\
\hline $\mathrm{O}(4)-\mathrm{Ni}(1)-\mathrm{O}(10)$ & $77.63(4)$ & $\mathrm{N}(3)-\mathrm{Ni}(1)-\mathrm{O}(4)$ & $96.47(4)$ & $\mathrm{O}(10)-\mathrm{Ni}(2)-\mathrm{O}(4)$ & $83.91(4)$ \\
$\mathrm{O}(4)-\mathrm{Ni}(1)-\mathrm{O}(1 \mathrm{~W})$ & $86.08(4)$ & $\mathrm{N}(3)-\mathrm{Ni}(1)-\mathrm{O}(7)$ & $91.81(4)$ & $\mathrm{N}(1)-\mathrm{Ni}(2)-\mathrm{O}(1)$ & $83.81(4)$ \\
$\mathrm{O}(7)-\mathrm{Ni}(1)-\mathrm{O}(4)$ & $165.05(4)$ & $\mathrm{N}(3)-\mathrm{Ni}(1)-\mathrm{O}(10)$ & $94.16(4)$ & $\mathrm{N}(1)-\mathrm{Ni}(2)-\mathrm{O}(4)$ & $169.18(4)$ \\
$\mathrm{O}(7)-\mathrm{Ni}(1)-\mathrm{O}(10)$ & $89.40(4)$ & $\mathrm{N}(3)-\mathrm{Ni}(1)-\mathrm{O}(1 \mathrm{~W})$ & $176.05(4)$ & $\mathrm{N}(1)-\mathrm{Ni}(2)-\mathrm{O}(10)$ & $103.13(4)$ \\
$\mathrm{O}(7)-\mathrm{Ni}(1)-\mathrm{O}(1 \mathrm{~W})$ & $85.06(4)$ & $\mathrm{N}(2)-\mathrm{Ni}(1)-\mathrm{N}(3)$ & $98.66(4)$ & $\mathrm{N}(1)-\mathrm{Ni}(2)-\mathrm{O}(5)$ & $100.19(4)$ \\
$\mathrm{O}(10)-\mathrm{Ni}(1)-\mathrm{O}(1 \mathrm{~W})$ & $83.41(3)$ & $\mathrm{O}(1)-\mathrm{Ni}(2)-\mathrm{O}(4)$ & $87.80(4)$ & $\mathrm{N}(4)-\mathrm{Ni}(2)-\mathrm{O}(1)$ & $176.94(5)$ \\
$\mathrm{N}(2)-\mathrm{Ni}(1)-\mathrm{O}(4)$ & $92.08(4)$ & $\mathrm{O}(1)-\mathrm{Ni}(2)-\mathrm{O}(5)$ & $84.21(3)$ & $\mathrm{N}(4)-\mathrm{Ni}(2)-\mathrm{O}(4)$ & $93.60(4)$ \\
$\mathrm{N}(2)-\mathrm{Ni}(1)-\mathrm{O}(7)$ & $98.97(4)$ & $\mathrm{O}(4)-\mathrm{Ni}(2)-\mathrm{O}(5)$ & $72.08(4)$ & $\mathrm{N}(4)-\mathrm{Ni}(2)-\mathrm{O}(5)$ & $93.62(4)$ \\
$\mathrm{N}(2)-\mathrm{Ni}(1)-\mathrm{O}(10)$ & $164.41(4)$ & $\mathrm{O}(5)-\mathrm{Ni}(2)-\mathrm{O}(10)$ & $155.78(4)$ & $\mathrm{N}(4)-\mathrm{Ni}(2)-\mathrm{O}(10)$ & $91.00(4)$ \\
$\mathrm{N}(2)-\mathrm{Ni}(1)-\mathrm{O}(1 \mathrm{~W})$ & $84.23(4)$ & $\mathrm{O}(10)-\mathrm{Ni}(2)-\mathrm{O}(1)$ & $91.85(4)$ & $\mathrm{N}(4)-\mathrm{Ni}(2)-\mathrm{N}(1)$ & $94.47(5)$ \\
\hline & & \multicolumn{1}{|c|}{} & & &
\end{tabular}

\section{Supplementary Material}

Supplementary crystallographic data have been deposited with the Cambridge Crystallographic Data Centre, CCDC No. 731857. Copies of this information may be obtained free of charge from The Director, CCDC, 12 Union Road, Cambridge CB2 1EZ, UK (Fax: +44 1223 336033; Email: deposit@ccdc.cam.ac.uk orwww: http://www.ccdc.cam.ac.uk). 


\section{References and Notes}

1. Eddaoudi, M.; Moler, D.B.; Li, H.; Chen, B.; Reineke, T.M.; O'Keeffe, M.; Yaghi, O.M. Modular chemistry: Secondary building units as a basis for the design of highly porous and robust metalorganic carboxylate frameworks. Acc. Chem. Res. 2001, 34, 319-330.

2. Fontes, A.P.S.; Bandarage, R.; Farrell, N.; Qu, Y.; Rauter, H.; Kelland, L.R. Synthesis, Characterization, and Cytotoxicity of Trifunctional Dinuclear Platinum Complexes: Comparison of Effects of Geometry and Polyfunctionality on Biological Activity. J. Med. Chem. 2000, 43, 3189-3192.

3. Huang, Y.S. Chemistry of Spicery oil; Shanghai Science and Technology Press: Shanghai, China, 1959; p. 333 (in Chinese).

4. Zhu, R.H.; Xue, Q.C. Handbook of Synthesis Practical Spicery; Light Industry Press: Beijing, China, 1986; p. 167 (in Chinese).

5. Praefcke, K.; Bilgin, B.; Pickardt, J.; Borowski, M. A novel platinum methylene complex. $J$. Organomet. Chem. 1999, 592, 155-161.

6. Elmali, A.; Elerman, Y.; Zeyrek, C.T.; Svoboda, I. Crystal Structure and Magnetic Properties of a Dinuclear Iron(III) Doubly Oxygen Bridged Schiff Base Complex. Z. Naturforsch. B Chem.Sci. 2003, 58, 433-437.

7. Yeap, G.Y.; Ha, S.T.; Ishizawa, N.; Suda, K.; Boey, P.L.; Mahmood, W.A.K. Synthesis, crystal structure and spectroscopic study of para substituted 2-hydroxy-3-methoxybenzalideneanilines. $J$. Mol. Struct. 2003, 658, 87-99.

8. Eran, B.B.; Singer, D.; Pickardt, J.; Praefcke, K. Thiocyanato-bridged platinum heterocycles: structure and properties of disc-like metallomesogens. J. Organomet. Chem. 2001, 620, 249-255.

9. Holm, R.H.; Evert, G.W.; Chakravorty, A. Metal Complexes of Schiff Bases and $\beta$-Ketoamines. Prog. Inorg. Chem. 1966, 7, 83-214.

10. Dharmaraj, N.; Viswanathamurthi, P.; Natarajan, K. Ruthenium(II) complexes containing bidentate Schiff bases and their antifungal activity. Transition Met. Chem. 2001, 26, 105-109.

11. Yalpani, M.; Hall, L.D. Some chemical and analytical aspects of polysaccharide modifications. 3. Formation of branched-chain, soluble chitosan derivatives. Macromolecules 1984, 17, 272-281.

12. Miyasaka, H.; Ieda, H.; Matsumoto, N.; Crescenzi, R.; Floriani, C. Assembling Bi-, Tri- and Pentanuclear Complexes into Extended Structures Using a Desolvation Reaction: Synthesis, Structure, and Magnetic Properties of Manganese(III)-Schiff-Base-Hexacyanoferrate Polymeric Compounds and Their Derived Extended Structures. Inorg. Chem. 1998, 37, 255-263.

13. Kato, M., Muto, Y. Factors affecting the magnetic properties of dimeric copper(II) complexes. Coord. Chem. Rev. 1988, 92, 45-83.

14. Iglesias, R.; Marcos, M.; Serano, J.L.; Sierra, T. Ferroelectric Behavior of Chiral Bis(salicylideneaniline) Copper(II), Vanadium(IV), and Palladium(II) Liquid Crystals. Chem. Mater. 1996, 8, 2611-2617.

15. Zhao, G.L.; Feng, Y.L.; Wen, Y.H. Syntheses, crystal structures and kinetic mechanisms of thermal decomposition of rare earth complexes with Schiff base derived from o-vanillin and ptoluidine. J. Rare Earths 2006, 24, 268-275. 
16. Li, H.Q.; Xian, H.D.; Liu, J.F.; Zhao, G.L. Catena-Poly[[di- $\mu$-chlorido-bis $\{[6-m e t h o x y-2-(4-$ methylphenyliminiomethyl)phenolato- $\left.\kappa^{2} \mathrm{O}, \mathrm{O}^{\prime}\right]$ cadmium(II)\}]-di- $\mu_{2}$-thiocyanato- $\left.\kappa^{2} \mathrm{~N}: \mathrm{S} ; \kappa^{2} \mathrm{~S}: \mathrm{N}\right]$. Acta Crystallogr., Sect. E: Struct. Rep. Online 2008, 64, m1593-m1594.

17. Yu, Y.Y.; Zhao, G.L.; Wen, Y.H. Syntheses, Characterizations, Crystal Structures and Antibacterial Activities of Two Zinc(II) Complexes with a Schiff Base Derived from o-Vanillin and p-Toluidine. Chinese J. Struct. Chem. 2007, 26, 1395-1402.

18. Nakamoto, K. Infrared and Raman spectra of Inorganic and Coordination Compounds, 5th ed.; Wiley \&Sons: New York, NY, USA, 1986; pp. 232-234.

19. Dey, M.; Rao, C.P.; Saarenketo, P.K.; Rissanen, K. Mono-, di- and tri-nuclear Ni(II) complexes of N-, O-donor ligands: structural diversity and reactivity. Inorg.Chem.Commun. 2002, 5, 924928.

20. Roesky, H.W.; Andruh, M. The interplay of coordinative, hydrogen bonding and $\pi-\pi$ stacking interactions in sustaining supramolecular solid-state architectures. A study case of bis(4-pyridyl)and bis(4-pyridyl-N-oxide) tectons. Coord. Chem. Rev. 2003, 236, 91-119.

21. Achar, B.N.; Brindley, G.W.; Sharp, J.H. Kinetics and mechanism of dehydroxylation process.III. Applications and limitations of dynamic methods. Proc. Int. Clay. Conf. Jerusalem 1966, 1, 67-73.

22. Sharp, J.H.; Wendworth, S.A. Kinetic analysis of thermogravimetric data. Anal. Chem. 1969, 41, 2060-2062.

23. Coats, A.W.; Redfern, J.P. Kinetic Parameters from Thermogravimetric Data. Nature 1964, 201, 68-69.

24. Sheldrick, G.M. SHELXS97 and SHELXL97. University of Göttingen: Göttingen, Germany, 1997.

Sample Availability: Samples of the compound is available from the authors.

(C) 2009 by the authors; licensee Molecular Diversity Preservation International, Basel, Switzerland. This article is an open-access article distributed under the terms and conditions of the Creative Commons Attribution license (http://creativecommons.org/licenses/by/3.0/). 